\title{
JACOB GRIMM: DA EXALTAÇÃO DA LÍNGUA ALEMÃ À LINGUÍSTICA DO SÉCULO XIX
}

\section{JACOB GRIMM: FROM THE EXALTATION OF THE GERMAN LANGUAGE TO 19TH CENTURY LINGUISTICS}

\author{
Raul de Carvalho Rocha \\ Universidade Federal de Alagoas \\ Maceió, Alagoas, Brasil \\ Núbia Rabelo Bakker Faria \\ Universidade Federal de Alagoas \\ Maceió, Alagoas, Brasil
}

RESUMO: O presente trabalho busca demonstrar a influência e o impacto dos ideais do Romantismo alemão no direcionamento das reflexões sobre a linguagem no século XIX, que contribuiu para o estabelecimento da Linguística como ciência. Enfatizar-se-á o alemão Jacob Grimm (1785-1863), conhecido pela compilação, com o seu irmão, Wilhelm Grimm (1786-1859), de contos infantis extraídos do folclore alemão (publicados entre 1812-1858) e pela formulação da nomeada primeira lei fonética. Influenciado pelo nacionalismo romântico, que se caracterizou por recusar o passado clássico e por promover a valorização da literatura e da língua nacionais, Grimm dedicou-se ao estudo das manifestações culturais genuinamente germânicas e da língua alemã, com vistas a enaltecer a identidade nacional. O resultado, entretanto, foi a importante descoberta da mutação fônica sistemática, observada na comparação entre o grego, o gótico, o latim e o sânscrito, que influenciará os rumos dos estudos linguísticos modernos. Partindo-se de uma contextualização histórica e exposição teórica sobre o Romantismo, relacionar-se-ão os ideais do movimento com a obra linguística de Grimm. Trata-se de uma pesquisa de natureza bibliográfica, teoricamente fundamentada em Robins (1979) e Morpurgo Davies (1998), obras voltadas para a historiografia linguística, e em Guinsburg (1978), no campo da teoria da literatura.

PALAVRAS-CHAVE: Grimm; Lei Fonética; Romantismo Alemão.

ABSTRACT: The present study seeks to demonstrate the 
influence and impact of the German Romanticism ideals on heading of the reflections about language in the 19th Century, which contributed for the establishment of Linguistics as Science. It will emphasize the German author Jacob Grimm (1785-1863), better known associated with his brother, Wilhelm Grimm (17861859), trough the compilation of fairy tales extracted from the German folklore (published between 18121858), and by the formulation of the recent called first phonetic law. Grimm, heavily biased by the romantic nationalism, featured by the refusal of the classical past and promoting the appreciation of a national literature and language, focused on the study of Germanic cultural manifestations and German language, truly from within its roots, aiming for a national identity. The result, however, was the important discovery of a systematic phonetic mutation, noticed trough comparisons among Greek, Gothic, Latin and Sanskrit languages and which will influence the directions of the modern Linguistic Studies. Starting from a historical contextualization and theoretical exposure about Romanticism, it will relate the movement ideals with Grimm's Linguistics work. This is a bibliographical research, theoretically based on Robins (1979) and Morpurgo Davies (1998), works directed to linguistic historiography, and on Guinsburg (1978), in the field of the literature theory.

KEYWORDS: Grimm; Phonetic Laws; German Romanticism. 


\section{INTRODUÇÃO}

A importância do Romantismo é ter sido o maior movimento recente que transformou a vida e o pensamento do mundo ocidental.

Isaiah Berlin (2013 [1999], p. 2-3)

O Romantismo pode ser definido não somente como um movimento cultural, filosófico e artístico, mas como um estado de espírito, "uma mentalidade permanente que não é exclusiva de uma época nem é monopolizada por ela" (BERLIN, 2013 [1999], p. 6). Emergiu, em finais do século XVIII, na região correspondente, hoje, à Alemanha e caracterizou-se por fazer surgir "uma tábua nova de valores que atingiu todos os domínios do pensamento humano, o artístico como o científico" (ELIA, 2005 [1978], p. 114). O estudioso alemão Jacob Grimm (1785-1863) pode ser considerado um exemplo ideal da afirmação anterior, visto que todas as suas obras, científicas e literárias, apresentam a visão do homem romântico do século XIX e estreito vínculo com o nacionalismo que o movimento suscitou em seu tempo. Então um reino não unificado, imerso em um obscurantismo intelectual e tecnológico em relação a nações como a França então o centro da cultura europeia de uma maneira geral —, a Alemanha dos séculos XVII e XVIII conviveu com a supervalorização da cultura latina, sobretudo a francesa, e assistiu ao completo desprezo pelas manifestações artísticas nacionais por parte de sua elite intelectual.

Nas últimas décadas do século XVIII, entretanto, uma mudança de paradigma atingiu o território alemão e instaurou uma "reação contra a palavra estrangeira e o domínio que ela exerceu sobre as categorias do pensamento" (BAKTHIN, 2006, p. 114), que se impôs com tamanha veemência às esferas intelectuais e estéticas da época que o Racionalismo e os padrões propostos pelo Classicismo não se conseguiram recuperar; tratava-se do Romantismo (HAUSER, 1995 , p. 664). Foi nas obras de filósofos como Jean-Jacques Rousseau (17121778) e Johann Gottfried von Herder (1744-1803), autores associados ao movimento conhecido por Sturm und Drang, um Pré-Romantismo, que ocorreu a germinação dos ideais antirracionalistas e patrióticos sobre os quais se fundamentaram os românticos dos séculos XVIII e XIX. O ambiente com o qual Jacob Grimm conviveu, portanto, foi marcado pelo desprezo à razão e pela exaltação da nacionalidade. Foram as concepções de língua, poesia e história de Herder, entretanto, que influenciaram profundamente o empreendimento de Jacob e de seu irmão, Wilhelm Grimm (1786-1859), em busca do enaltecimento da cultura e língua germânicas por meio da compilação de contos de fadas medievais e, mais tarde, do estabelecimento da obra Deutsche Grammatik (Gramática Germânica), que foi decisiva para a consolidação de uma nova disciplina que se realizou com êxito em solo alemão. Foi Jacob Grimm, porém, quem exerceu atuação especial nesse cenário. 
Comumente considerado como um dos principais responsáveis pela ascensão exitosa da Linguística a que se assistiu, Jacob Grimm conseguiu incluir os estudos realizados à época acerca das chamadas "línguas clássicas" em perspectiva histórica propriamente dita. Priorizando o grupo germânico, o qual comparou ao grego, ao latim e ao sânscrito, Grimm conseguiu formular a primeira lei de mudança fonética a que a posteridade chamou "Lei de Grimm". Entretanto, as razões que o conduziram à importante descoberta da mutação fonética sistemática no grupo germânico possuíram natureza nitidamente políticoideológicas. Pretende-se, com este artigo, refletir sobre a maneira como os ideais românticos que permeavam o pensamento de Grimm, sobretudo o nacionalismo característico desse "estado de espírito", interferiu no direcionamento dos estudos linguísticos emergentes, contribuindo para a consolidação definitiva de uma disciplina, a Linguística, que se conseguiu tornar uma ciência objetiva e autônoma, apesar de suas origens nitidamente ideológicas.

\section{JACOB GRIMM: UM FILHO DE SUA ÉPOCA}

Conforme Robins (1979) ressaltou, os trabalhos dos primeiros linguistas do século XIX têm de ser analisados levando-se em consideração o contexto histórico em que os seus autores estavam inseridos. Tenhamos em mente, desde então, o marco principal do momento em que o linguista alemão Jacob Grimm realizou a sua obra: o nacionalismo romântico. Deve-se observar que Grimm, enquanto um "filho de sua época", nas palavras do próprio Robins, foi um simpatizante dos ideais românticos, que provocaram a irrupção de um orgulho desmedido pela língua e cultura germânicas; e, de fato, toda a sua obra foi nitidamente contagiada pelo "estado de espírito" que o Romantismo suscitou em seu tempo. É preciso, porém, entender as principais características do movimento romântico que habitavam a mentalidade de Grimm para perceber a sua influência nas reflexões do autor. Para isso, é necessária uma apreciação sobre o contexto em que estava inserida a Alemanha no século em que ocorreu o advento do Romantismo propriamente dito e que o influenciou.

Primeiramente, não existia a nação alemã, mas um reino não unificado, constituído por diversos estados semiautônomos que compartilhavam entre si apenas "uma realidade linguística, cultural e literária" (CARPEAUX, 2014). É a essa "realidade" que se está chamando "Alemanha" neste artigo. Ademais, tratava-se de uma nação econômica, tecnológica e culturalmente atrasada sem qualquer influência na esfera política europeia (HAUSER, 1995, p. 672). Tal situação resultou no isolamento do território em relação ao Ocidente, e as demais nações europeias consideravam-no, ao longo do século XVII, um país "sem literatura" e "uma nação de iletrados". A própria língua alemã era considerada pelos franceses, por exemplo, uma "língua a ser utilizada para falar com criados e com cavalos", e mesmo os intelectuais alemães se comunicavam em francês, conforme Carpeaux (2014). A introdução tardia do Iluminismo (Aufklärung) à nação, no século XVII, fez-se notar, pois, como uma tentativa de "reabilitação dos valores" da Alemanha e de sua reintegração à Europa. Observou-se, neste 
período, a valorização excessiva e a idealização da cultura francesa a tal ponto que os valores nacionais foram esquecidos (BORNHEIM, 2005 [1978], p. 78), e os alemães adotaram ostensiva e servilmente o estilo francês (HAUSER 1995, p. 600); a Aufklärung, "com sua mentalidade fortemente tingida pela França", representou, pois, "[...] a fase menos nórdica da cultura alemã", nas palavras de Gerd Bornheim (2005 [1978], p. 84).

No entanto, foi esse mesmo caráter excessivamente estrangeiro que a impediu de alcançar repercussão mais abrangente em território alemão. Os ideais da Aufklärung, amplamente difundidos pelas camadas mais elevadas da sociedade, não foram abraçados com a mesma veemência pelas camadas mais populares (HAUSER, 1995, p. 597). Consequentemente, em seu auge, por volta de 1740, era possível perceber os sinais de seu esgotamento na Alemanha. Em 1748, por exemplo, a publicação de Der Messias, do poeta Friedrich Gottlieb Klopstock (1724-1803), iniciava a literatura genuinamente alemã, nas palavras de Carpeaux (2014), ao "germanizar" o hexâmetro em vez de reproduzir a métrica clássica. Entre 1767 e 1769, Gothold Ephraim Lessing (1729-1781) realizou fortes ataques nutridos de "ódio patriota" ao predomínio do teatro clássico francês nos palcos alemães (CARPEAUX, 2014). Era o prenúncio da rebeldia que se instalaria, na Alemanha, contra o predomínio das convenções estéticas do Classicismo. Nos anos seguintes, com o movimento Sturm und Drang (Tempestade e Ímpeto), assistiu-se à "revolta do sentimento contra a razão" (CARPEAUX, 2014) e ao distanciamento das influências greco-latinas, racionalistas e iluministas, que se tornaram o marco principal do Romantismo (SILVA, 1979, p. 464-6), cuja consolidação propriamente dita ocorreu nas duas últimas décadas do século XVIII (NUNES, 2005 [1978], p. 52).

Não causa espanto, pois, ter sido Jacob Grimm um entusiasta dessa corrente "antirracionalista" e "anti-iluminista" iniciada pelo Sturm und Drung. Junto ao seu irmão, Wilhelm Grimm, Jacob dedicar-se-á ao estudo e à recuperação da literatura e lendas germânicas da Idade Média (GOOCH, 1913), e o retorno a esse momento histórico não foi desmotivado. O período medieval, povoado por um folclore místico e caracterizado pela religiosidade, foi amplamente denegrido pelo Racionalismo iluminista (SILVA, 1979, p. 481), hostil à religião e ao "poder do irracional" manifestado na experiência religiosa (HAUSER, 1995, p. 609-11). O Romantismo, com a sua mentalidade "anticlássica", investirá na "reabilitação da Idade Média" (DUARTE, 2011, p. 99) como uma forma de reagir ao "desencanto" e à sobriedade do "racionalismo ateu" do Século das Luzes, e a sua busca por um passado genuinamente germânico, afastado das influências greco-latinas, fez da Idade Média o ambiente ideal para os românticos alemães (HAUSER, 1995, p. 610; SILVA, 1979, p. 482).

Essa reação contra a hegemonia da cultura estrangeira em território alemão que irrompeu com o Romantismo (BAKTHIN, 2006, p. 114) levou à recusa dos padrões estéticos do Classicismo e à contestação de sua atemporalidade (DUARTE, 2011, p. 99-103). Sob a influência do filósofo Jean-Jacques Rousseau (1712-1778), os românticos anunciaram a primazia do homem primitivo e de sua espontaneidade "constituída pelos simples sentimentos e gostos estéticos" em relação ao homem urbano, que permitiu à civilização desfigurar os seus 
sentimentos e apreços estéticos por meio de regras e convenções. Exaltava-se, pois, a liberdade do gênio criativo e sua autenticidade em oposição à generalização do fazer artístico, isto é, a repreensão do gênio detentor da criação imaginativa incomensurável por meio de convenções a respeito da composição poética fundamentadas na normatização da mimesis e na racionalidade (FALBEL, 2005 [1978], p. 103-4). E foi a glorificação do chamado bon sauvage (o "bom selvagem"), de seu primitivismo e de sua espontaneidade (BORNHEIM, 2005 [1978]; SILVA, 1979) que fez com que Jacob Grimm declarasse, em seu ensaio Gedanken über Mythos, Epos und Geschichte, de 1813, por exemplo, a supremacia da chamada "poesia popular", resultado do trabalho "inconsciente" e "puramente espontâneo da comunidade", em relação à "poesia consciente" (GOOCH, 1913, p. 56).

A referência de Grimm a "uma poesia popular" foi o resultado da conviç̧ão dos românticos sobre o intrínseco vínculo existente entre o povo, a sua língua e a sua cultura, introduzida pelo filósofo Johann Gottfried von Herder (1744-1803), assim como a valorização das diferenças linguísticas e culturais defendida pelo pensador (MORPURGO DAVIES, 1998, p. 83). Herder prezou a peculiaridade de cada povo devido às particularidades de tempo e espaço em que cada um se encontrava inserido. Isso representou não somente uma crítica ao Classicismo francês, que buscava universalizar as culturas, mas também a exaltação da cultura nacional devido aos fatores particulares dos quais emergiu (NUNES, 2005 [1978], p. 59). Foi Herder quem introduziu na estética romântica a importância do historicismo (SILVA, 1979, p. 82), concepção esta que propiciou o advento da Linguística (CÂMARA JR., 1975, p. 12) e constituiu as bases dos estudos linguísticos de Grimm, tratados mais adiante.

Sob a influência do pensamento de Rousseau, Herder valorizou o povo (Volk), por meio do qual se teria acesso às raízes da nacionalidade, pois considerava que as condições particulares de existência dos povos - seja em relação a tempo, a espaço ou a momento histórico - teriam sido por eles associadas e constituído, pois, as características das nações (FALBEL, 2005 [1978], p. 59). Sobre a poesia, afirmou ser o resultado de uma experiência do "sentir" (Gefühl) dos povos primeiros relacionada ao ambiente em que os mesmos se encontravam; portanto, um "produto de condições naturais e históricas", conforme notou Nachman Falbel (2005 [1978], p. 43). Sendo a linguagem poética a "língua-mãe" da humanidade, sob o ponto de vista do filósofo, as línguas seriam, então, um "repositório cultural de um povo", enquanto as diferenças linguísticas, o "fruto de diferentes experiências dos povos". A Herder, portanto, é atribuída "a descoberta da língua como meio de individualização das nações" (FALBEL, 2005 [1978], p. 43). Ao conceber um vínculo entre a língua, o pensamento, a literatura e a unidade nacionais (ROBINS, 1979, p. 122), Herder proporcionou aos estudiosos da linguagem um ponto de vista alternativo em relação à filologia clássica - que tinha por foco de pesquisa as línguas grega e latina -, pois tornou dignos de estudo os "falares incultos", os dialetos e "as línguas longínquas" das clássicas. (LEROY, 1989, p. 32).

Foram a concepção de Herder acerca da necessidade de se estudar as literaturas populares em suas próprias línguas para que elas fossem 
compreendidas adequadamente (ROBINS, 1979, p. 121) e a crítica realizada por Friedrich Schlegel (1778-1829) de que os estudos literários apenas podem ser bem-sucedidos se aliados ao conhecimento gramatical que levaram Jacob Grimm ao estudo filológico da língua germânica a fim de aprimorar a sua pesquisa sobre a literatura alemã. Durante as suas investigações sobre a língua, Grimm observou a existência de dois tipos de alternância vocálica em períodos distintos da língua germânica; essa constatação tê-lo-ia convencido da importância de um estudo histórico em Linguística, ao qual ele se dedicou definitivamente por volta de 1816 (MORPURGO DAVIES, 1998, p. 137). A isto, uniu-se a publicação, no mesmo ano, da obra de Franz Bopp (KOERNER, 1990, p. 8-9), em que a relação de "parentesco" existente entre o gótico e o sânscrito - língua sagrada dos povos hindus - foi reafirmada. Essa descoberta foi abraçada com entusiasmo pelos alemães, pois thes proporcionou um fato histórico preciso que os permitiria se libertarem da hegemonia greco-latina (AUROUX, 2000).

\section{JACOB GRIMM E A LINGUÍSTICA DO SÉCULO XIX}

A importância de Jacob Grimm para a Linguística Histórica é indiscutível, pois foi ele um dos "promotores da Gramática Comparada" (SARFATI; PAVEAU, 2006 [2003], p. 31) e, conforme afirmou Auroux (2000, p. 159), quem "de fato introduziu a dimensão histórica" nos estudos em questão. Diferentemente do dinamarquês Rasmus Rask e do alemão Franz Bopp, que se atentaram ao estabelecimento de relações de parentesco entre línguas, Grimm enfatizou o desenvolvimento histórico das línguas germânicas (CÂMARA JR., 1975m p. 40), ao qual teve acesso por meio da extensa quantidade de dados distribuídos em sequência de catorze séculos (FARACO, 2007, p. 135). As suas análises foram divulgadas em sua Deutsche Grammatik (Gramática Germânica), cuja primeira edição foi publicada em 1819 e prezou os estudos morfológicos (KOERNER, 1990 , p. 14), seguindo-se mais quatro volumes entre 1822 e 1837. A princípio, Grimm enfatizou a análise do gótico - língua dos povos Godos Orientais e a mais antiga língua germânica de que se tem registro -, preservado pela tradução parcial de uma Bíblia realizada no século IV pelo bispo Wulfilas (CÂMARA JR., 1975, p. 41).

No entanto, a segunda edição de Deutsche Grammatik, realizada quatro anos depois, foi a mais importante para os estudos linguísticos. Direcionando, desta vez, a sua atenção ao desenvolvimento fonético do grupo germânico (SARFATI; PAVEAU, 2006 [2003], p. 31), Grimm abordou em 595 páginas dessa edição ao que chamou "mutações fonéticas" ("Lautverschiebung") - que, posteriormente, foram batizadas de "Lei de Grimm" (AUROUX, 2000, p. 160). Observou ele que as mudanças consonantais pelas quais passavam as línguas germânicas em diferentes estados históricos se apresentavam regulares e se correlacionavam com outras línguas da posteriormente chamada "família indoeuropeia" (ROBINS, 1978, p. 138). Por esse motivo, o grupo germânico se transformou em exceção notável entre as línguas estudadas. A seguinte tabela ilustra as observações do linguista: 
Tabela 1.

\begin{tabular}{|c|c|c|c|c|c|c|c|c|c|}
\hline$g r$. & $\mathrm{P}$ & $\mathrm{B}$ & $\mathrm{F}$ & $\mathrm{T}$ & $\mathrm{D}$ & $\mathrm{TH}$ & $\mathrm{K}$ & $\mathrm{G}$ & $\mathrm{CH}$ \\
\hline got. & $\mathrm{F}$ & $\mathrm{P}$ & $\mathrm{B}$ & $\mathrm{TH}$ & $\mathrm{T}$ & $\mathrm{D}$ & $\mathrm{H}$ & $\mathrm{K}$ & $\mathrm{G}$ \\
\hline a.a.a & $\mathrm{B}(\mathrm{V})$ & $\mathrm{F}$ & $\mathrm{P}$ & $\mathrm{D}$ & $\mathrm{Z}$ & $\mathrm{T}$ & $\mathrm{G}$ & $\mathrm{CH}$ & $\mathrm{K}$ \\
\hline
\end{tabular}

Fonte: AUROUX (2000, p. 160)

Tomando-se dois estados da língua germânica, o gótico (got.) e o altoalemão antigo (a.a.a.), e comparando-os ao grego ( $g r$.), Grimm percebeu que as consoantes surdas - ou tenuis, terminologia grega utilizada por ele - do grego $(p, t, k)$ tornaram-se aspiradas no gótico $(f, t h, h)$, e, posteriormente, transformaram-se em médias $(b, d, g)$ no alto-alemão antigo; as consoantes gregas médias $(b, d, g)$ tornaram-se surdas $(p, t, k)$ em gótico e, em alto-alemão antigo, evoluíram para aspiradas $(f, z, c h)$; enfim, as aspiradas gregas $(f$, th, $c h)$ tornaramse médias $(b, d, g)$ em gótico e surdas $(p, t, k)$ em alto-alemão antigo (CÂMARA JR, 1975, p. 43). Nessas mudanças, Grimm percebeu não somente a alteração de um fonema para outro, mas uma alternância de intensidade fonética em cada grupo consonantal (AUROUX, 2000, p. 160-1). Mutação fonética regular foi por ele igualmente apreendida com a comparação entre o gótico e as demais línguas da família indo-europeia - o grego, o latim e o sânscrito.

Tabela 2.

\begin{tabular}{|c|c|c|c|c|c|c|c|c|c|}
\hline gr. & $\mathrm{P}$ & $\mathrm{B}$ & $\mathrm{F}$ & $\mathrm{T}$ & $\mathrm{D}$ & $\mathrm{TH}$ & $\mathrm{K}$ & $\mathrm{G}$ & $\mathrm{CH}$ \\
\hline got. & $\mathrm{F}$ & $\mathrm{P}$ & $\mathrm{B}$ & $\mathrm{TH}$ & $\mathrm{T}$ & $\mathrm{D}$ & $\mathrm{H}$ & $\mathrm{K}$ & $\mathrm{G}$ \\
\hline lat. & $\mathrm{P}$ & $\mathrm{B}$ & $\mathrm{F}$ & $\mathrm{T}$ & $\mathrm{D}$ & $\mathrm{T}$ & $\mathrm{C}$ & $\mathrm{G}$ & $\mathrm{H}$ \\
\hline sans. & $\mathrm{P}$ & $\mathrm{B}$ & $\mathrm{BH}$ & $\mathrm{T}$ & $\mathrm{D}$ & $\mathrm{DH}$ & $\mathrm{S}$ & $\mathrm{J}$ & $\mathrm{H}$ \\
\hline
\end{tabular}

Fonte: LYONS (1979, p. 27)

Conforme expõe a tabela, Grimm notou que o gótico (got.) comportava os fonemas $f, p$, th e $t$ onde outras línguas da família indo-europeia invariavelmente comportavam, respectivamente, os fonemas $p, b, t$ e $d$. Portanto, enquanto em gótico se tinha "fotos", em latim (lat.), em grego ( $g r$.) e em sânscrito (sans.) havia "pedis", "podós" e "padas", respectivamente. Para explicar a discrepância entre a forma gótica e as demais, o linguista formulou a hipótese de que a alteração fonética encontrada teria ocorrido em algum período remoto da língua germânica, de modo que as consoantes aspiradas $(b h, d h, g h)$, sonoras $(b, d, g)$ e surdas $(p, t$, $k$ ) do grupo indo-europeu passaram, respectivamente, a consoantes sonoras $(b, d$, $g$ ), surdas $(p, t, k)$ e aspiradas ( $p h, t h, k h)$ no grupo germânico (LYONS, 1979, p. 27-8).

Com essa hipótese, Grimm propôs, portanto, que a sistematicidade da correspondência entre as línguas tinha relação com o fluxo histórico e que as mudanças linguísticas obedeciam a processos regulares (FARACO, 2007, p. 136). Apesar de Rask ter intuído essa sistematização anteriormente, foi Grimm quem 
conseguiu evidenciar a regularidade das transformações (SARFATI; PAVEAU, 2006 [2003], p. 31-2). Aparentes exceções à regra foram detectadas pelo autor, mas ele não se preocupou em explicá-las, pois concluiu serem as mutações sonoras "uma tendência que não se segue em todos os casos" (ROBINS, 1979, p. 139). Esses desvios provocaram intenso debate entre os linguistas do século XIX, tendo sido, posteriormente, esclarecidos por Karl Verner (1846-1896) e a "Lei de Verner". A elucidação das razões às exceções acabou por reforçar a crença no princípio de regularidade das mudanças fonéticas (FARACO, 2007, p. 142-3), e Grimm notabilizou-se por ter sido o primeiro linguista a conceber uma teoria em que se evidenciavam as transformações fonéticas sistemáticas de uma língua em relação às comparações morfológicas de seus antecessores (AUROUX, 2000 p. 160). Com o seu trabalho, portanto, aliou o estudo comparativo ao histórico, originando a denominação por que os estudos linguísticos desse período são conhecidos: Linguística Histórico-Comparativa (FARACO, 2007, p. 135).

Os estudos de Grimm notabilizaram-se, inclusive, pelo seu empirismo, ao qual o próprio Grimm se mostrava fiel: "Sou avesso a conceitos lógicos gerais na gramática; eles emprestam à definição um rigor e uma coerência ilusórios, e obstruem a observação, na qual eu vejo a alma da ciência da linguagem" (apud AUROUX, 2000, p. 159). Tal empirismo, porém, não era desmotivado. Acreditava ele que a sua busca pelo "espírito nacional", que se refletia na literatura popular e na língua germânicas, apenas seria alcançado pelo empirismo. "Se ignorarmos a observação que, indubitavelmente confiável, constitui o âmago de toda teoria desde o início, nunca nos aproximaríamos do insondável espírito da língua", disse ele (apud AUROUX, 2000, p. 159). Além disso, reflete o seu entusiasmo romântico antirracionalista, visto ter ele se declarado completamente contrário a raciocínios lógicos nas reflexões sobre a língua, sustentando as suas análises em dados empíricos e observáveis (MORPURGO DAVIES, 1998, p. 138), o que configurou uma clara oposição aos estudos dos racionalistas franceses (BORNHEIM, 2005 [1978], p. 80), que "buscavam a certeza do conhecimento [...] nas verdades irrefutáveis da razão humana", conforme afirmou Robins $(1979$, p. 89). Outro traço do Romantismo em sua obra linguística se mostrou nas conclusões a que chegou sobre a mutação fonética do gótico em relação às demais línguas da família indo-europeia. Em Geschichte der deutschen Sprache, publicada em 1848, o linguista declarou:

De certo ponto de vista, a mutação fonética parece-me uma característica de horror e repulsão à civilização, que outros povos mais pacíficos evitaram, mas que está relacionada ao violento progresso dos povos germânicos rumo à liberdade e à sua luta por ela, o que marcou o início da Idade Média e acarretou a transformação da Europa (apud AUROUX, 2000, p. 159).

Com isto, é possível perceber como os ideais do Romantismo alemão contagiaram o seu trabalho. Conforme afirmou Robins (1978, p. 139), Grimm utilizou as ideias de Herder "para explicar o estreito vínculo de uma nação e sua língua com a dimensão história da linguagem" e, por isso, percebeu a mutação 
fonética como "uma primitiva forma de manifestação de independência por parte dos antepassados dos povos germânicos". Na realidade, o próprio fato de Jacob ter-se dedicado ao estudo das línguas germânicas configurou um traço romântico. Como observou o linguista francês Antoine Meillet, o Romantismo alemão nutriu forte interesse "por um passado independente da cultura greco-latina e aproveitava-se de tudo o que a história do passado e a exploração do mundo faziam para alargar as vistas estreitas do Classicismo", tanto em relação à literatura quanto em relação às línguas (apud ELIA, 2005 [1978], p. 123). Disto se pode apreender a recolha de contos populares alemães e os estudos de Jacob Grimm sobre a língua germânica como "reflexos de uma crescente e generalizada onda de orgulho nacional pela língua alemã, orgulho que começou a manifestarse nos princípios do século XVIII [...]", nas palavras de Robins (1979, p. 139).

\section{CONSIDERAÇÕES FINAIS}

O objetivo de Grimm, desde o princípio, esteve inserido no nacionalismo romântico. Teria o autor declarado ao fim da vida: "Todas as minhas obras se relacionam com minha pátria, de cujo solo derivam as suas forças" (apud GOOCH, 1913, p. 61). A comparação do gótico com as "línguas clássicas" e o sânscrito consistiu, pois, em uma maneira de exaltar a sua desprezada língua, a qual, longe de ser uma língua inferior, cujo uso seria restrito a "falar com criados e cavalos", estava genealogicamente vinculada às hipervalorizadas línguas grega e latina, fato que conseguiu comprovar empiricamente. Com isso, Grimm pretendeu exaltar o próprio povo alemão, a quem a língua refletiria (MORPURGO DAVIES, 1998, p. 139), sob a ótica romântica. Outro traço de sua mentalidade romântica se revelou em sua abordagem metodológica, caracterizada por ser empirista, histórica e indutiva (KOERNER, 1990, p. 13), visto que partia da apreensão da realidade para se chegar às conclusões, contando com o auxílio de uma "intuição intelectual", valorizada pelos românticos, e não por meio de raciocínios lógicos, que tanto ele quanto os românticos desprezaram (BORNHEIM, 2005 [1978], p. 111).

Tudo isso foi o reflexo de um momento em que os nacionalistas alemães necessitavam afirmar a sua unidade nacional e reagir contra a hegemonia estrangeira que se instalara em seu território, sobretudo a francesa, tendo sido o parentesco com as "línguas clássicas", portanto, um fato histórico preciso que permitiu a Grimm fazê-lo. Disso resultou a sua "interpretação nacionalista" sobre as mutações fonéticas, nas palavras de Robins (1979:, p. 139), e a referência aos povos greco-romanos e à "superioridade" dos povos germânicos o evidencia, uma vez que percebeu ele a mutação fonética como resultado da proximidade dos antepassados germânicos do idealizado "homem primitivo". Os povos romanos, saturados de convenções tanto no fazer artístico quanto na esfera intelectual, foram algo a que os antepassados dos alemães reagiram devido ao seu "progresso" em relação aos demais. Afinal, foram os povos germânicos quem puseram fim à dominação do Império Romano do Ocidente, em 476 da Era Cristã, iniciando a Idade Média e provocando "a transformação da Europa" a que 
se referiu Grimm. A mudança fonética das línguas germânicas, portanto, representaria esse progresso e distanciamento dos povos germânicos de outros mais "civilizados".

Embora o seu desejo de fazer reconhecer o valor da língua e do povo alemão tenha resultado em sua "entusiasta e ingênua explanação" e revelado a "atitude mística a respeito da linguagem" que o conduziu em seu estudo, conforme proferiu Câmara Júnior (1975, p. 43), é preciso reconhecer, porém, a importância dos estudos de Grimm para a Linguística, pois foi ele um dos comparatistas que "lançaram os fundamentos da abordagem histórica da linguagem", tendo contribuído para que a ciência da linguagem se autonomizasse (CÂMARA JR., 1975, p. 44). A descoberta da mutação consonantal e a explanação que forneceu a respeito de sua sistematicidade tornaram-se basilar para o estudo histórico da linguagem, pois foi o primeiro modelo de lei fonética sobre o qual a Linguística Histórica se pôde apoiar rumo a uma perspectiva mais científica (LEROY, 1989, p. 31-2; CÂMARA JR, 1975, p. 43), tendo sido a sua "lei fonética" a responsável por configurar "a base e a estrutura da família indoeuropeia e de outras famílias linguísticas" (ROBINS, 1979, p. 138). As suas crenças ingênuas a respeito da mudança linguística, entretanto, embasam a conclusão de que o advento da Linguística Histórico-Comparativa em concomitância com a irrupção do Romantismo não ocorreu por acaso (ELIA, 2005 [1975], p. 121), pois, conforme observou Auroux (2000, p. 164), "as razões por trás do surgimento da Linguística Indo-Europeia não foram apenas científicas, mas igualmente ideológicas".

\section{REFERÊNCIAS}

AUROUX, Sylvain; BERNARD, Gilles; BOULLE, Jacques. Histoire des Idées Linguistiques, Tome 3: L'hégémonie du comparatisme. Liège-Bruxelas: Pierre Mardaga, 2000.

BAKHTIN, Mikhail. Marxismo e filosofia da linguagem: problemas fundamentais do Método Sociológico na Ciência da Linguagem. 12. ${ }^{a}$ edição. São Paulo: HUCITEC, 2006.

BERLIN, Isaiah. The Roots of Romanticism. 2. ${ }^{\mathrm{a}}$ edição. Princeton: Princeton University Press, 2013 [1999].

BORNHEIM, Gerd. "Filosofia do Romantismo". In: GUINSBURG, Jacob (Org.). O Romantismo. 4. a edição. São Paulo: Perspectiva, 2005 [1978].

CÂMARA JR., Joaquim Mattoso. História da linguística. Petrópolis: Vozes, 1975.

CARPEAUX, Otto Maria. A história concisa da literatura alemã. São Paulo: Girassol Brasil, 2014. 
DUARTE, Pedro. Estio do tempo: Romantismo e Estética Moderna. Rio de Janeiro: Zahar, 2011.

ELIA, Sílvio. "Romantismo e Linguística". In: GUINSBURG, Jacob (Org.). O Romantismo. 4. ' edição. São Paulo: Perspectiva, 2005 [1978].

FALBEL, Nachman. "Fundamentos históricos do Romantismo". In: GUINSBURG, Jacob (Org.). O Romantismo. 4. edição. São Paulo: Perspectiva, 2005 [1978].

FARACO, Carlos Alberto. Linguística Histórica: uma introdução ao estudo da história das línguas. 2. edição. São Paulo: Parábola Editorial, 2007.

GOOCH, G. P. History and Historians in the Nineteenth Century. Londres: Longmans, Green, and Co., 1913.

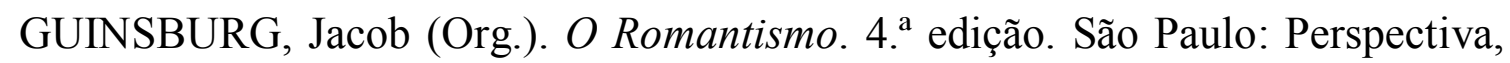
2005 [1978].

HAUSER, Arnold. História social da arte e da literatura. São Paulo: Martins Fontes, 1995.

KOERNER, Konrad. "Jacob Grimm's Place" In:The Foundation of Linguistics as a Science. In: ANTONSEN, Elmer H.; MARCHAND, James Woodrow; ZGUSTA, Ladislav (Org.). The Grimm Brothers and the Germanic Past. Amsterdã: John Benjamins Publishing, 1990.

LEROY, Maurice. As grandes correntes da Linguística Moderna. São Paulo:Cultrix, 1989.

LYONS, John. Introdução à Linguística Teórica. São Paulo: Ed. Nacional, 1979.

MORPURGO DAVIES, Ana. History of Linguistics. Nova Iorque: Addison Wesley Longman Inc., 1998.

NUNES, Benedito. "A visão romântica”. In: GUINSBURG, Jacob (Org.). O Romantismo. 4. ' edição. São Paulo: Perspectiva, 2005 [1978].

ROBINS, Robert H. Pequena história da Linguística. Rio de Janeiro: Ao Livro Técnico, 1979.

SARFATI, Georges Elia; PAVEAU, Anne-Marie. As grandes teorias da Linguística: da Gramática Comparada à Pragmática. São Carlos: Claraluz, 2006 [2003]. 
SILVA, Vítor Manuel de Aguiar e. Teoria da literatura. 3. ${ }^{a}$ edição. Coimbra: Livraria Almedina, 1979.

Raul de Carvalho Rocha Raul.Caarvalho@gmail.com

Núbia Rabelo Bakker Faria NRBFaria@uol.com.br

Recebido em: 9 mar. 2018 Aceito em: 7 jun. 2018 Publicado em: 19 ago. 2018 